\title{
PATTERNS OF DROWNING AND NEAR DROWNING IN NSW
}

Ann Williamson and Marcia Schmertmann

NSW Injury Risk Management Research Centre

University of New South Wales

An analysis of drowning in Australia showed that, overall, rates of drowning are low compared to other injuries. ${ }^{1}$ In NSW between 1995 and 1999, drowning was the sixth most common injury-related cause of death, and neardrowning was the eighth most common cause of injury-related hospitalisation. ${ }^{2}$ However, as these are population-based estimates, the rates underestimate the risk involved in exposure to water-related hazards. As many people are not regularly exposed to bodies of water, the risk for those who are is significantly higher than that suggested by the population rate. This article describes the relationship between exposure to water and the risk of drowning.

\section{METHODS}

Data on drownings in NSW was obtained for 1992-1999 from the Australian Bureau of Statistics (ABS) for all drowning-related E-coded death records (E830, E832, and E910).

Data on near drowning in NSW was obtained for 19921999 from the NSW Department of Health Inpatient Statistics Collection for all near drowning-related E-coded hospitalisations (E830, E832, and E910).

\section{RESULTS}

Between 1995 and 1999, 465 NSW residents died from drowning; a rate of 1.5 per 100,000 residents (Figure 1).

\section{FIGURE 1}

RATE OF DROWNING IN NSW BY YEAR, 1992-1999

Death rate per 100,000

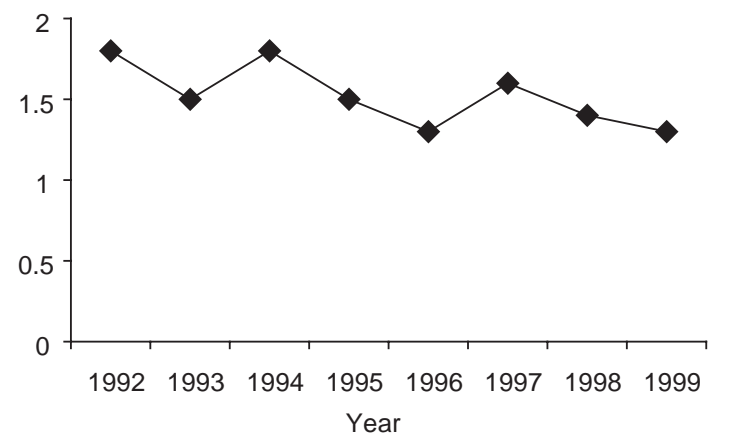

Source: ABS mortality data and population estimates, Australian Bureau of Statistics,
The majority of NSW residents who drowned were male (79 per cent).

Of these 465 drowning deaths in NSW, approximately 15 per cent were children less than five years of age. Figure 2 shows the rate of drowning in NSW by age group, 19921999.

The locations of the drownings in NSW included areas of natural water (41 per cent), swimming pools ( 29 per cent), boat-related locations (15 per cent), bathtubs (eight per cent) and other and unspecified locations (seven per cent). Males accounted for 85 per cent of all drownings in natural bodies of water, almost all boat-related deaths and around three-quarters of all swimming pool deaths. Females drowned in bathtubs more than twice as often as males.

Between 1995 and 1999, 1,168 NSW residents were hospitalised for a near drowning event; a rate of 3.9 per 100,000 residents (Figure 3). Just over two-thirds of the near drowning hospitalisations were males (68 per cent).

Of 1168 hospitalisations due to near drowning, approximately 35 per cent were children less than five years of age. Figure 4 shows the rate of hospitalisation due to near drowning in NSW by age group, 1992-1999.

Natural water settings (38 per cent), swimming pools (20 per cent), boat-related locations (10 per cent) and bathtubs (nine per cent) were the most common locations for near drownings that required hospitalisation. For 23 per cent of near drowning cases, the location was classified as 'other' and was not specified.

\section{EXPOSURETOWATER AND DROWNING RISK}

Children under five years of age were found to be at significantly higher risk of drowning and near-drowning than any other age group, especially in swimming pools and bathtubs. Drowning in this age group occurred mainly during the daytime and in all seasons of the year. ${ }^{1}$ In contrast, males over the age of five years are most likely to drown in open water, while boating or swimming, mainly during the summer and on public holidays. This reflects when they have the most chance to have access to water activities. ${ }^{1}$

The article by Schmertmann and Williams, ${ }^{1}$ and the NSW Injury Profile produced by the NSW Injury Risk Management Research Centre, ${ }^{2}$ suggest avenues for intervention to reduce drowning and near-drowning. Action is needed most in reducing the risk of drowning and near-drowning among babies and small children, and among young males. Older people are also at greater risk of drowning and near-drowning than the general 


\section{FIGURE 2}

RATE OF DROWNING IN NSW BY AGE GROUP, 1992-1999

Death rate per 100,000

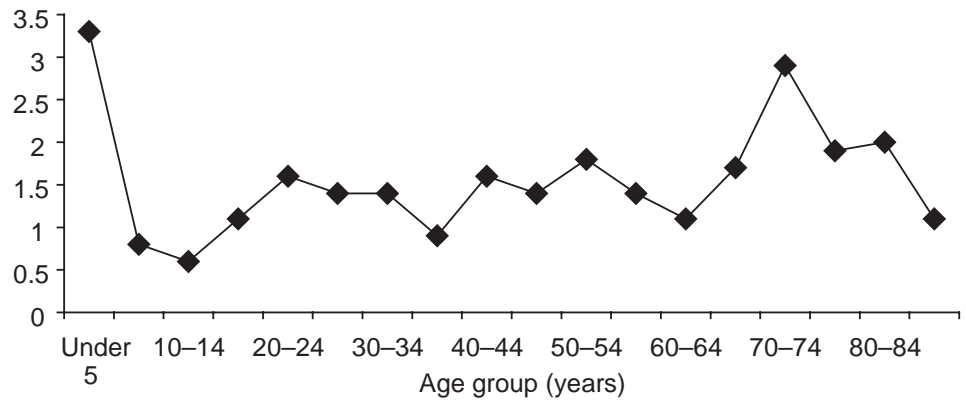

Source: ABS mortality data and population estimates, Australian Bureau of Statistics.

\section{FIGURE 3}

RATE OF NEAR DROWNING HOSPITALISATION IN NSW BY YEAR, 1992-1999

Hospitalisation rate per 100,000

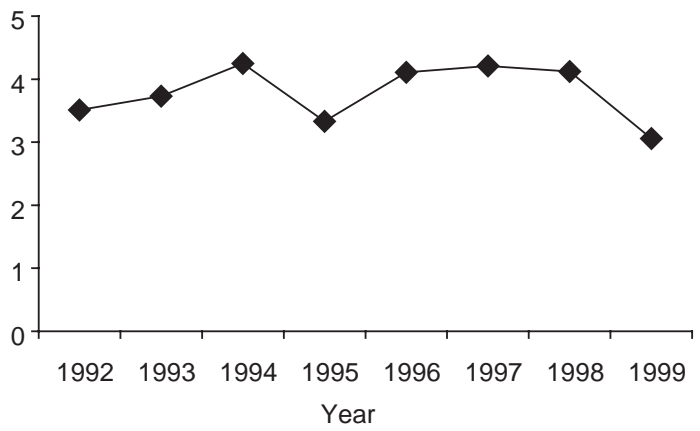

Source: NSW Health Inpatient Statistics and ABS population estimates (HOIST). Epidemiology and Surveillance Branch, NSW Department of Health.

\section{FIGURE 4}

RATE OF NEAR DROWNING HOSPITALISATION IN NSW BY AGE GROUP, 1992-1999

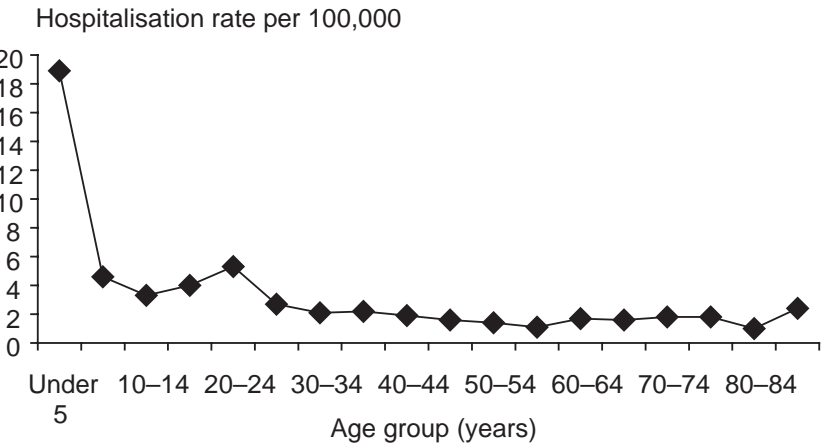

Source: NSW Health Inpatient Statistics and ABS population estimates, (HOIST). Epidemiology and Surveillance Branch, NSW Department of Health. 
population. These results suggest that intervention activities, which target these groups, should focus on boating and swimming.

\section{REFERENCES}

1. Schmertmann M and Williamson AM. Analysis of drowning in Australia and pilot analysis of near-drowning in New South Wales. Sydney: Australian Water Safety Council, 2000.

2. NSW Injury Risk Management Research Centre. NSW Injury Profile 2001. Sydney: NSW Injury Risk Management Research Centre, 2001.

\section{NSW WATER SAFETYTASKFORCE}

\section{Rebecca Mitchell}

Injury Prevention and Policy Unit

NSW Department of Health

Currently, there are an average of 87 drownings in NSW each year. ${ }^{1}$ Drowning represents the sixth most common cause of accidental death in NSW. ${ }^{2}$ As described by Williamson and Schmertmann in the previous article, certain age groups demonstrate higher incidences of drowning, and males in general are more likely to die as a result of drowning than females. As incidents of drowning and near-drowning are considered to be largely preventable, they are a major safety concern for the community. This article describes the NSW Safety Taskforce and the intersectoral activities ensuing to reduce the incidence of drowning and near-drowning in NSW.

The NSW Minister for Sport and Recreation established the NSW Water Safety Taskforce, in recognition of the importance of water safety and the need for a coordinated approach. The Taskforce is comprised of 14 member organisations (Table 1).

\section{TABLE 1}

\section{NSW WATER SAFETYTASKFORCE: MEMBER ORGANISATIONS}

Australian Professional Ocean Lifeguard Association

Austswim NSW

Farmsafe NSW

Kellogg Australia

Royal Life Saving Society, NSW Branch

Surf Life Saving NSW

Waterways Authority

NSW Community Relations Commission

NSW Department of Education and Training

NSW Department of Local Government

NSW Department of Health

NSW Department of Sport and Recreation.

NSW Local Government and Shires Association

NSW Premier's Department

The Taskforce developed the NSW Water Safety Framework 2001-2003, to assist in developing and presenting strategic advice to the government on matters related to water safety. The overall goals of the framework are to:
- achieve a coordinated and collaborative framework for water safety in NSW;

- ensure an effective and strategic management of water safety in NSW.

Three priority areas have been identified in the framework - education, standards, and evidence-which are accompanied by seven objectives and 19 strategic directions. A lead agency has been identified for each strategic direction: the NSW Department of Sport and Recreation for education, the Waterways Authority for standards, and the NSW Department of Health for evidence.

\section{Priority-Education}

The education component of the Taskforce has included:

- launch of SafeWaters in 2001;

- televised public awareness campaign for SafeWaters;

- development of the SafeWaters Web site;

- development of SafeWaters information brochures;

- a poster competition, run primarily in schools with large numbers of children from non-English speaking backgrounds, which aimed to illustrate key water safety messages.

\section{Priority-Standards}

The standards component of the Taskforce has included a review of all policy, legislation, regulations, and standards related to water safety, particularly in the areas of:

- minimum training standards and registration of lifeguards;

- collection of information on near-drownings at beaches and public swimming pools;

- compliance and enforcement of residential swimming pool fencing;

- safety issues around rockfishing.

\section{Priority-Research}

Research is currently being conducted in a number of areas for the Taskforce, including:

- a feasibility trial of collecting data using a minimum dataset for water safety at a number of NSW beaches and public swimming pools;

- collection of information on the number of people who take part in specific water-related activities (such as rockfishing) and/or visit particular aquatic 